\title{
Indicadores de desempenho diferenciam empresas do mesmo segmento?
}

Do performance indicators differentiate companies from the same segment?

¿Los indicadores de desempeño diferencian a las empresas en el mismo segmento?

\section{Luiz Henrique Figueira Marquezan}

Doutor em Ciências Contábeis na Universidade do Vale do Rio dos Sinos (UNISINOS)

Professor do Departamento de Ciências Contábeis da Universidade Federal de Santa Maria (UFSM)

Endereço: Av. Roraima, n॰ 1000, Prédio 74-C, Sala 4345, Cidade Universitária, Bairro Camobi CEP: 97105-900 - Santa Maria/RS - Brasil

E-mail: luizmarquezan@gmail.com

Telefone: (55) 3220.9298

\section{Marivane Vestena Rossato}

Doutora em Economia Aplicada na Universidade Federal de Viçosa (UFV)

Professora do Departamento de Ciências Contábeis da Universidade Federal de Santa Maria (UFSM)

Endereço: Av. Roraima, n॰ 1000, Prédio 74-C, Sala 4345, Cidade Universitária, Bairro Camobi CEP: 97105-900 - Santa Maria/RS - Brasil

E-mail: marivavest@gmail.com

Telefone: (55) 3220.9298

\section{Bernardo Cohen Ely}

Bacharel em Ciências Contábeis pela Universidade Federal de Santa Maria (UFSM)

Endereço: Av. Roraima, n॰ 1000, Prédio 74-C, Sala 4345, Cidade Universitária, Bairro Camobi CEP: $97105-900$ - Santa Maria/RS - Brasil

E-mail: becohenely@hotmail.com

Telefone: (55) 3220.9298

\section{Tiago Ribas Fogaça}

Bacharel em Ciências Contábeis pela Universidade Federal de Santa Maria (UFSM)

Endereço: Av. Roraima, n 1000, Prédio 74-C, Sala 4345, Cidade Universitária, Bairro Camobi CEP: 97105-900 - Santa Maria/RS - Brasil

E-mail: f_tiagoribas@yahoo.com.br

Telefone: (55) 3220.9298

Artigo recebido em 25/01/2018. Revisado por pares em 02/04/2018. Reformulado em 27/03/2019. Recomendado para publicação em 27/03/2019 por Carlos Eduardo Facin Lavarda (Editor-Chefe). Publicado em 31/03/2019. 


\title{
Resumo
}

O objetivo deste estudo foi identificar a capacidade dos indicadores de rentabilidade e lucratividade em produzir subsídios para analistas e investidores, por meio da diferenciação das empresas de um mesmo segmento de atuação. Tal abordagem segue a linha contingencial. Para isso, foram analisadas 17 empresas do segmento de edificações da B3, em 22 trimestres. Os dados, secundários, foram coletados do website da B3, adotando-se os indicadores: ROA, Margem Bruta, Margem EBITDA e Margem Líquida. Os dados foram analisados por meio de estatística descritiva e Teste de Kruskal Wallis, com o procedimento de comparações múltiplas. Os resultados possibilitaram avaliar cada indicador e empresa, identificando os que mais as diferenciam. Concluiu-se que os quatro indicadores apresentam diferenças estatisticamente significativas entre as empresas, porém em índices menores a 40\% das comparações possíveis. Assim, o uso de técnicas estatísticas contribui para a identificação sobre variações significativas de desempenho entre as companhias, bem como demonstra as semelhanças em um mesmo setor econômico e pode contribuir no julgamento de analistas e investidores. O estudo discute tais impactos e a relevância desse tipo de análise por eles.

Palavras-chave: Indicadores de desempenho; Rentabilidade; Lucratividade; Teste de Kruskal Wallis; B3

\begin{abstract}
The objective of this study was to identify the capacity of profitability indicators in producing subsidies for analysts and investors through the differentiation of the companies of the same industry. This approach follows the contingency line. To this, were analyzed 17 companies from the real estate industry from B3, in 22 trimesters. The data, secondary, were collected from $B 3$ website, using the indicators: ROA, Gross Margin, EBITDA Margin and Net Profit Margin. The data were analyzed through descriptive statistics and Kruskal Wallis test, with the multiple comparisons process. The results made possible to evaluate each of indicator and company, identifying those that most differentiate them. As a conclusion, the four indicators showed statistically significant differences between the companies, but in levels less than $40 \%$ of the possible comparisons. Thus, the use of statistical techniques contributes to the identification of significant variations in performance between companies, as well as demonstrates the similarities in the same industry and can contribute to the judgment of analysts and investors. The study discusses these impacts and the analysis relevance to them.
\end{abstract}

Keywords: Performance indicators; Profitability; Kruskal Wallis test; B3

\section{Resumen}

El objetivo del estudio fue identificar la capacitad de indicadores de rentabilidad en producir subsidios para los analistas e los inversores a través de la diferenciación de firmas en uno mismo segmento. Para esto, fueron analizadas 17 compañias del segmento de construcción de la B3, en 22 trimestres. Los datos, secundarios, fueran colectados del website de la B3, de los indicadores: ROA, Margen Bruta, Margen EBITDA, Margen Neta. Los datos fueran analizados por estadísticas descriptivas y Teste de Kruskal Wallis, con el procedimiento de comparaciones múltiples. Los resultados permitirán evaluar cada indicador y compañia, identificando las que más se diferencian. Se concluye que los cuatro indicadores han presentado diferencias estadisticamente significantes entre las firmas, pero con niveles abajo de $40 \%$ de las comparaciones posibles. Así, el uso de técnicas estadísticas contribuye para la identificación de variaciones significativas de desempeño entre las empresas, y muestra las similitudes en uno mismo segmento económico y puede contribuir no juicio de analistas e inversores. El estudio discute estos impactos e la relevancia de esto tipo de análisis para ellos.

Palabras clave: Indicadores de desempeño; Rentabilidad; Teste de Kruskal Wallis; B3 


\section{Introdução}

O mercado de capitais é um mecanismo de distribuição de valores mobiliários, que tem o objetivo de gerar liquidez aos títulos emitidos pelas empresas e viabilizar o seu processo de capitalização, aproximando-as dos detentores de capital. Porém, para atuar, o investidor necessita tomar decisões sobre a compra de ações, títulos ou participação em carteiras de investimentos (SILVA, 2013). Assim, dependendo da qualidade da informação que este investidor obtiver, pode resultar em um ótimo ou péssimo negócio. Em outras palavras, ele precisa de informações sobre as empresas que demonstrem diferenças entre elas para decidir em qual investir, permitindo realizar comparações e julgamentos para tomar a melhor decisão. $\mathrm{Na}$ esteira desse, os analistas financeiros emitem opiniões sobre as empresas e setores. Uma forma de subsídio para ambos é a informação contábil.

A contabilidade, além de confeccionar os demonstrativos contábeis, oferece o ferramental da análise financeira, que organiza as informações contábeis e agrega outras informações relevantes para auxiliar os usuários na avaliação, tomada de decisões e na orientação de suas ações. Visa, portanto, suprir cada usuário com o conjunto de informações que melhor atenda às suas necessidades (SILVA, 2013).

Nesta linha, a análise financeira oferece indicadores de desempenho para avaliação das empresas por meio das demonstrações contábeis, dentre eles os de rentabilidade, que representam a capacidade de uma empresa gerar lucros com o próprio patrimônio e os de lucratividade que medem a relação do lucro sobre com as operações realizadas na competência de cada exercício. Constituem, desta forma, conjunto capaz de gerar informações alinhadas aos interesses dos detentores de capital, ao julgar o resultado econômico de forma comparativa ao montante de capital disponível e ao montante de capital que circula pelas operações da companhia. São as medidas mais utilizadas por analistas, possuem baixo custo de obtenção, especialmente quando comparadas a medidas não financeiras e outras medidas operacionais de divulgação não obrigatória (PACE; BASSO; SILVA, 2003).

Com estas ferramentas de análise, os investidores podem comparar empresas, desde que tais indicadores demonstrem variações entre elas. Evidências são identificadas na literatura sobre a forma de utilização para análise em modelos tradicionais (MILTERSTEINER, 2003), a comparação do modelo tradicional com outras abordagens: EVA ${ }^{\circledR}$ (ALMEIDA et al., 2016); Modelo Fleuriet (KITZBERGER; PADOVEZE, 2016; SILVA; ALMEIDA, 2018); metodologias multicritério (BORTOLUZZI et al., 2011); comparação com índices-padrão por setor (DUARTE; LAMOUNIER, 2007). Também, os autores discutem sua capacidade em gerar subsídios para segregar empresas vencedoras e perdedoras (GUAY, 2000; TAVARES; SILVA, 2012), boas e más opções de investimento em empresas de alto risco e menor governança (GALDI, 2008), demonstrando a validade no uso dos indicadores financeiros para decisões de investimento (GUAY, 2000), a captação de efeitos de mudanças contábeis (SILVA; SANCHES; IGARASHI, 2019) e a aplicação para decisões da própria gestão (SILVA; COUTO; CARDOSO, 2016).

Dentre as bases de discussão que motivam estudos nesta linha estão a relevância das técnicas de análise das demonstrações contábeis (ALMEIDA et al., 2016) e a qualidade da informação obtida no mercado de capitais, pela divulgação realizada pelas empresas (ex.: BIDDLE; HILARY; VERDI, 2009; BUSHMAN; SMITH, 2001; LEUZ; VERRECHIA, 2000) e pela presença de diferentes níveis de assimetria informacional (AKERLOF, 1970). Os custos de obter dados adicionais sobre o desempenho (JENSEN; MECKLING, 1976) que reflitam com maior sensibilidade as ações dos gestores (LAMBERT, 2001) pode inviabilizar seu uso. Ainda, a análise de muitos dados está sujeita à racionalidade limitada (EISENHARDT, 1989; JENSEN; MECKLING, 1976; MACEDO; FONTES, 2009) e podem gerar erros de decisão (CONLISK, 1996) e prejudicar a capacidade de previsão das pessoas (SHEA, 2015). 
Nesta linha, ao analisar empresas do mesmo setor, é adequado pensar na necessidade de uma abordagem contingencial (DONALDSON, 2001), visto que estão sujeitas a semelhantes interferências externas (ambiente), e os indicadores financeiros podem não ser suficientes para demonstrar diferenças significativas entre elas. Caso seja este o comportamento dos indicadores, incorre na necessidade de investidores e analistas buscarem informações adicionais para julgar as companhias ou analisá-las pelo desempenho do segmento, o que influencia no conjunto de informações, o tempo de análise e as bases para decisão, elevando ou reduzindo o custo de acesso à informação.

Considerar o setor com um fator comum é tratamento tanto em análises específicas de cada setor (ex.: ALMEIDA et al., 2016; ELING; JIA, 2018), quanto utilizado como variável de controle em pesquisas. Considerando tais aspectos, o objetivo do estudo busca identificar a capacidade dos indicadores de rentabilidade e lucratividade em produzir subsídios para investidores através da diferenciação das empresas de um mesmo segmento de atuação. Para analisar tal realidade, optou-se pelo segmento de edificações, utilizando informações sobre o desempenho trimestral de 2012 a 2017. Segmento escolhido por ser um dos maiores da B3, com ampla maioria das empresas participantes do Novo Mercado pois, ainda que não garanta totalmente, pode ser considerado como proxy para melhor qualidade das informações apresentadas, considerando as exigências de práticas ligadas à Governança Corporativa e evidências em favor disso (SILVEIRA et al., 2009), incluindo a redução do gerenciamento de resultados por escolhas contábeis (MARTINEZ, 2011).

A motivação para realização deste trabalho é demonstrar indicadores que apresentem, ou não, diferenças entre as empresas, e em que nível, fortalecendo a importância da informação contábil no mercado de capitais e na comparação das empresas, por meio do uso de ferramenta estatística passível de uso por não especialistas. Com isso, contribui para a literatura sobre indicadores da análise das demonstrações contábeis, discutindo seu poder de explicação para uso no mercado de capitais, com abordagem contingencial, pelo fator ambiente, ligado a um setor econômico. Ainda, ao diferenciar as empresas por meio da técnica de comparações múltiplas, do teste de Kruskal Wallis, apresenta subsídios para analistas e investidores utilizarem nas suas atividades, bem como para pesquisadores que procurem analisar o uso da informação contábil no ambiente das empresas, especialmente aquelas de capital aberto, tendo por base o custo de obter informações. Contribuição adicional para as escolhas de informações diante do número reduzido de dados financeiros que investidores não profissionais utilizam (PENNINGTON; KELTON, 2016), procurando reduzir os efeitos dos vieses de decisão, mesmo em investidores profissionais (MACEDO; FONTES, 2009).

Para isso, além dessa introdução, a pesquisa conta com uma revisão de literatura e apresentação da hipótese a ser testada. Segue com os passos metodológicos utilizados, os resultados obtidos e a lista das referências consultadas.

\section{Informação Contábil e Hipótese de Pesquisa}

Alinhado à estrutura conceitual básica da contabilidade brasileira, originada pelo processo de harmonização às normas internacionais, a relevância da informação contábil é característica necessária para relação desta com seu usuário. Considerada pela capacidade de influenciar uma decisão, seja pelo seu uso efetivo ou pela não consideração desta diante do conhecimento sobre tal (CPC00, 2011), parece adequado discutir a utilidade dessa informação em uma decisão de investimento.

Nessa linha, e, considerando a contabilidade como elemento importante no processo de análise empresarial, pela corrente fundamentalista (MILTERSTEINER, 2003), o uso de indicadores da análise das demonstrações contábeis pode satisfazer a característica qualitativa da relevância. Pautado nas bases da análise fundamentalista para investimentos, que procura 
avaliar ativos negociáveis, identificando aqueles mal precificados (KOTHARI, 2001), e no uso dessas informações para exercitar elementos preditivos (OLSON; MOSSMAN, 2003; PIOTROSKI, 2000), o conjunto de informações contábeis espelha situação atual e passada de uma organização, permitindo que seus usuários possam julgar seu desempenho. Com isso, potencialmente realizam decisões de investimento com maior assertividade.

Para isso, analisar indicadores que apresentem diferenças significativas entre as opções de investimentos pode agilizar o processo, reduzir os custos de obter informações e efeitos da racionalidade limitada pelo excesso de informações a serem processadas (EISENHARDT, 1989; JENSEN; MECKLING, 1976; MACEDO; FONTES, 2009). Caso isso ocorra, o usuário poderá julgar diretamente por dados contábeis, reduzindo a necessidade de informações adicionais, gerando menor custo.

Por outro lado, semelhanças no desempenho financeiro não geram informações suficientes para decidir entre as opções, e a demanda por dados adicionais gera custos aos investidores, especialmente de tempo e esforço, sendo ponderada pelos benefícios percebidos relevância e utilidade (KULVIWAT et al., 2004), principalmente em informações não financeiras sem obrigatoriedade de divulgação (PACE; BASSO; SILVA, 2003). Como contraponto, diante da maior igualdade de desempenho financeiro entre as companhias, o usuário, ao optar pela análise de um setor econômico, poderá julgar opções como igualmente válidas e dividir os recursos investidos em diferentes ativos, pulverizando o risco.

A literatura sobre o tema apresenta evidências de aplicabilidade das técnicas de análise das demonstrações contábeis, por meio de seus indicadores, tanto pelo modelo tradicional quanto pela combinação com outras técnicas, por vezes comparando-os com o objetivo de demonstrar alguma evolução. Os resultados apontados, mesmo que apresentem críticas sobre o modelo tradicional (ex.: ALMEIDA et al., 2016), não deixam de enfatizar a importância da técnica de análise como lastro para analistas e investidores em suas atividades e decisões (GUAY, 2000; KITZBERGER; PADOVEZE, 2016; SILVA; ALMEIDA, 2018), assim como para uso da gestão de cada empresa (SILVA; COUTO; CARDOSO, 2016).

Alinhado a esta literatura, o presente trabalho discute o uso de técnicas estatísticas para análise de indicadores e comparações entre empresas, pela estatística descritiva e o uso de teste não-paramétrico (Kruskal Wallis), alternativa aplicada a amostras pequenas, como são compostos os segmentos de atuação da B3, em que os dados não apresentam distribuição normal (fator também ligado ao número de observações).

Adicionalmente, é necessária atenção aos aspectos ligados ao ambiente. Em um mesmo setor ou segmento de atuação, podem ocorrer semelhanças maiores entre as companhias e seus desempenhos, devido a elementos comuns que impactam todas, tal como demanda, opções de fornecimento, ambiente de crédito, político, legal e econômico, etc. Na literatura o setor ou o segmento são tratados como representativos do ambiente da empresa, tornando-as comparáveis quanto aos níveis de incerteza deste (BURNS; STALKER, 1961; CHILD, 1972; LARWENCE; LORSCH, 1967). Por reagirem a este ambiente, as companhias acabam por assemelhar-se em diferentes aspectos, uma visão contingencial, sob pena de perda de desempenho (DONALDSON, 2001). Desta maneira, a capacidade de demonstrar diferenças é potencialmente reduzida quando analisadas empresas do mesmo segmento de atuação, em especial aos indicadores que demonstrem a performance operacional.

Por outro lado, diante das evidências encontradas na literatura, citadas na introdução deste estudo, sobre a efetividade no uso das informações contábeis para decisões de investimento, incluindo a comparação com o desempenho do setor (DUARTE; LAMOUNIER, 2007) e a previsibilidade de desempenho das companhias (GUAY, 2000; TAVARES; SILVA, 2012), esta pesquisa apresenta a seguinte hipótese: 


\section{H1: Indicadores de desempenho financeiro de rentabilidade e lucratividade demonstram diferenças significativas entre empresas do mesmo segmento.}

Essa abordagem, de cunho contingencial (DONALDSON, 2001), pode contribuir para a análise e o julgamento das decisões de investimentos, à medida que o usuário da informação avalia inicialmente sua qualidade pela capacidade de apresentar semelhanças ou diferenças. Os passos de pesquisa adotados neste trabalho para testar H1 são apresentados no próximo tópico.

\section{Procedimentos Metodológicos}

\subsection{Variáveis de pesquisa}

A pesquisa apresenta uma abordagem quantitativa, com uso de dados, secundários, coletados em bases públicas, documentos disponibilizados pelas empresas e pela B3. O levantamento dos dados do período foi realizado por meio dos relatórios das empresas, apresentados trimestralmente (Informações Trimestrais - ITR) e, para o último trimestre de cada ano, através dos relatórios anuais (Demonstrações Financeiras Padronizadas - DFP) subtraído dos valores dos três primeiros trimestres. As observações contemplam 22 trimestres, do $1^{\circ}$ trimestre de 2012 ao $2^{\circ}$ trimestre de 2017.

Os dados são todos em forma de saldos contábeis, retirados das demonstrações contábeis, relacionados e suas respectivas contas utilizadas (Quadro 1), procedimento realizado na segunda quinzena de outubro de 2017.

\section{Quadro 1 - Demonstrações e contas contábeis}

\begin{tabular}{|l|l|}
\hline \multicolumn{1}{|c|}{ Demonstração } & \multicolumn{1}{c|}{ Contas contábeis } \\
\hline Balanço Patrimonial & Ativo Total e Patrimônio Líquido Consolidado \\
\hline Demonstração do Resultado & $\begin{array}{l}\text { Receita de Vendas de Bens e/ou Serviços; Resultado Bruto; Resultado da } \\
\text { Equivalência Patrimonial; Resultado Antes do Resultado Financeiro e } \\
\text { dos Tributos e Lucro/Prejuízo Consolidado do Período }\end{array}$ \\
\hline $\begin{array}{l}\text { Demonstração do Fluxo de Caixa - } \\
\text { Método Indireto }\end{array}$ & Depreciações e Amortizações \\
\hline
\end{tabular}

Fonte: elaboração própria.

A análise dos dados baseou-se na obtenção e estudo das seguintes demonstrações contábeis: Balanço Patrimonial, Demonstração do Resultado e Demonstração dos Fluxos de Caixa; com a finalidade de calcular um indicador de rentabilidade líquida, o Retorno sobre o Ativo (Return on Assests - ROA), e três indicadores de lucratividade: Margem bruta, Margem EBITDA (lucro antes dos impostos, juros, depreciações e amortizações) e a Margem líquida (Quadro 2).

Quadro 2 - Variáveis utilizadas na pesquisa

\begin{tabular}{|c|l|l|}
\hline Variável & \multicolumn{1}{|c|}{ Nome } & \multicolumn{1}{c|}{ Forma de medição } \\
\hline ROA & $\begin{array}{l}\text { Retorno } \\
\text { sobre o ativo }\end{array}$ & $\begin{array}{l}\text { Percentual, obtido pela razão entre o Lucro/Prejuízo Líquido do Período e o Ativo } \\
\text { Total. }\end{array}$ \\
\hline MB & $\begin{array}{l}\text { Margem } \\
\text { bruta }\end{array}$ & $\begin{array}{l}\text { Percentual, obtido pela razão entre o Resultado Bruto e a Receita de Vendas de } \\
\text { Bens e/ou Serviços. }\end{array}$ \\
\hline MEBITDA & $\begin{array}{l}\text { Margem } \\
\text { EBITDA }\end{array}$ & $\begin{array}{l}\text { Percentual, obtido pela razão entre o EBITDA e Receita de Vendas de Bens e/ou } \\
\text { Serviços. }\end{array}$ \\
\hline ML & $\begin{array}{l}\text { Margem } \\
\text { líquida }\end{array}$ & $\begin{array}{l}\text { Percentual, obtido pela razão entre o Lucro/Prejuízo Consolidado do Período e a } \\
\text { Receita de Vendas de Bens e/ou Serviços. }\end{array}$ \\
\hline
\end{tabular}

Fonte: elaboração própria. 
Para chegar ao Lucro Operacional, elemento não declarado nas demonstrações contábeis, foi realizada a subtração entre o Resultado Antes do Resultado Financeiro e dos Tributos e o Resultado da Equivalência Patrimonial, ambos da Demonstração do Resultado. Para o cálculo do EBITDA, fez-se a soma do Lucro Operacional e os gastos com Depreciações e Amortizações, obtidos na Demonstração dos Fluxos de Caixa.

Inicialmente, também seria utilizada a variável Retorno sobre o Patrimônio Líquido (Return on Equity - ROE), mas optou-se pela exclusão deste, devido a observações com Patrimônio Líquido negativo. Tal fato resultaria na exclusão de empresas da amostra, prejudicando o número de observações para os testes estatísticos.

\subsection{População e amostra}

A população é composta pelas 18 empresas (Quadro 3) do segmento de edificações listadas na B3 em outubro de 2017. A denominação das empresas, ao longo do trabalho, é tratada na forma dos nomes de pregão.

Tendo a intenção de identificar semelhanças e diferenças nos indicadores de desempenho das empresas, optou-se por selecionar apenas um segmento de atuação, reduzindo efeitos do ambiente que resultassem nessa diferença, fator contingencial (DONALDSON, 2001). O segmento de edificações foi escolhido por ser um dos maiores dentre os listados na $\mathrm{B} 3$ e com a maioria das empresas atendendo às exigências do maior nível de governança corporativa (GC), isto é, aderiram ao Novo Mercado (NM), elevando a confiabilidade das informações nos dados, incluindo o menor gerenciamento de resultados (MARTINEZ, 2011).

\section{Quadro 3 - Empresas da amostra}

\begin{tabular}{|c|l|l|c|}
\hline $\mathbf{N}^{\mathbf{0}}$ & \multicolumn{1}{|c|}{ Razão Social } & \multicolumn{1}{|c|}{ Nome de Pregão } & $\begin{array}{c}\text { Segmento de } \\
\text { GC }\end{array}$ \\
\hline 1 & CONSTRUTORA ADOLPHO LINDENBERG S.A. & CONST A LIND & - \\
\hline 2 & CONSTRUTORA TENDA S.A. & TENDA & NM \\
\hline 3 & CR2 EMPREENDIMENTOS IMOBILIARIOS S.A. & CR2 & NM \\
\hline 4 & CYRELA BRAZIL REALTY S.A.EMPREEND E PART & CYRELA REALT & NM \\
\hline 5 & DIRECIONAL ENGENHARIA S.A. & DIRECIONAL & NM \\
\hline 6 & EVEN CONSTRUTORA E INCORPORADORA S.A. & EVEN & NM \\
\hline 7 & EZ TEC EMPREEND. E PARTICIPACOES S.A. & EZTEC & NM \\
\hline 8 & GAFISA S.A. & GAFISA & NM \\
\hline 9 & HELBOR EMPREENDIMENTOS S.A. & HELBOR & NM \\
\hline 10 & JHSF PARTICIPACOES S.A. & JHSF PART & NM \\
\hline 11 & JOAO FORTES ENGENHARIA S.A. & JOAO FORTES & - \\
\hline 12 & MRV ENGENHARIA E PARTICIPACOES S.A. & MRV & NM \\
\hline 13 & PDG REALTY S.A. EMPREEND E PARTICIPACOES & PDG REALT & NM \\
\hline 14 & RODOBENS NEGOCIOS IMOBILIARIOS S.A. & RODOBENS & NM \\
\hline 15 & ROSSI RESIDENCIAL S.A. & ROSSI RESID & NM \\
\hline 16 & TECNISA S.A. & TECNISA & NM \\
\hline 17 & TRISUL S.A. & TRISUL & NM \\
\hline 18 & VIVER INCORPORADORA E CONSTRUTORA S.A. & VIVER & NM \\
\hline
\end{tabular}

Fonte: Adaptado do website da B3 (2017).

Após a coleta dos dados foi possível perceber que a empresa VIVER apresentou Receita Líquida negativa em diversos períodos, inviabilizando o uso dos indicadores de lucratividade. Dessa forma, foi excluída da amostra, resultando no total de 17 empresas (k). Os procedimentos de tratamento e análise dos dados são apresentados no próximo tópico. 


\subsection{Tratamento e análise dos dados}

Os dados foram tabulados no Microsoft Excel para calcular os indicadores analisados no software Statistica 7, para obtenção dos parâmetros estatísticos utilizados na análise. Inicialmente, algumas observações apresentaram dados fora do padrão esperado, a saber: gastos com depreciações e amortizações negativas, ou seja, com saldo credor no trimestre; receita líquida negativa, ou seja, com saldo devedor no período. Todos os períodos que apresentaram Depreciações e Amortizações negativas foram ajustados para a média do ano utilizando o dado retirado das Demonstrações Financeiras Padronizadas anuais; os demais trimestres do mesmo ano foram igualmente substituídos pela média, não incorrendo em montante superior para o ano. Segundo identificado nas notas explicativas, tais ocorrências foram resultado de revisão da vida útil, ao final do período. Isso pode ser analisado pelas ocorrências de saldo negativo apenas no último trimestre. Assim, procedimentos adotados pelas empresas, de adequação às normas contábeis, praticados de forma isolada no último trimestre, alteraram o padrão das informações, em que foi adotada a alternativa descrita.

Alinhado a isto, nas empresas que apresentaram valores de Receita Líquida negativa, os dados foram ajustados pela média do ano, com reflexos em todos os trimestres. Foi possível perceber que procedimentos de avaliação de ativos a receber e a segregação dos juros, por meio da avaliação a valor presente, foram as causas, novamente procedimento de adequação às normas de contabilidade para avaliação do valor dos elementos patrimoniais. Também foi identificado, nos relatórios de administração das empresas que apresentaram Receita de Vendas de Bens e/ou Serviços negativa, um alto volume de distratos, tanto pela falta de recursos para finalização das obras quanto pela crise econômica ter afetado seus clientes. Os ajustes realizados foram igualmente adotados para as demais contas de resultado (Resultado Bruto, Lucro/Prejuízo Consolidado do Período e EBITDA), reduzindo distorções entre a receita, as depreciações e amortizações, e o resultado obtido em cada indicador, mantendo o resultado consolidado anual de cada companhia.

Para análise foram adotados dois procedimentos: estatística descritiva; e o teste de Kruskal Wallis para analisar semelhanças e diferenças nos desempenhos entre as empresas. Para o cálculo da estatística descritiva, primeira parte dos resultados, foram utilizados os parâmetros: média, mediana, desvio padrão, coeficiente de variação $(\mathrm{CV})$, máximo e mínimo.

$\mathrm{Na}$ segunda parte, foram testados, por variável, se os dados provêm de uma mesma população (não podem ser considerados diferentes) ou se apresentam diferenças significativas. Sendo os dados organizados em trimestres, optou-se pela análise de dados não pareados para $\mathrm{k}$ amostras. Inicialmente, foi necessário analisar a distribuição dos dados, pela aderência à distribuição normal, pelos testes Kolmogorov-Sminorv e Lilliefors. Em todos os parâmetros foi utilizado o predito por Siegel (2006). A hipótese nula de ambos os testes prevê que as observações seguem uma distribuição normal. Desta forma, há intenção de aceitar tal hipótese, ao nível de 5\%, ou seja, espera-se p-valor superior a 5\%. Os resultados apontam para rejeição ao nível de $1 \%$ (p-valor $<0,01$ ) em todas as variáveis, demonstrando que a distribuição dos dados não se assemelha à normal.

Sendo possível considerar sub-amostras (empresas) de forma não pareada por trimestre, estando sujeitas a semelhantes interferências econômicas e políticas, o teste de Kruskal Wallis foi utilizado, em que se tomou por base o nível de significância de 5\%. No teste de Kruskal Wallis, verifica-se a hipótese nula $\left(\mathrm{H}_{0}\right)$ contra a hipótese alternativa $\left(\mathrm{H}_{1}\right) . \mathrm{H}_{0}$ é a posição esperada da observação, ou seja, quando não há diferenças entre os grupos. Em caso de rejeição de $\mathrm{H}_{0}$, o teste resulta em p-valor $<5 \%$ e então o resultado é de que ao menos um dos grupos é diferente dos demais.

Diante de dessemelhanças entre os dados, esses foram sujeitos à análise de comparações múltiplas, que permite identificar quais sub-amostras são estatisticamente diferentes. Para isso 
é utilizada a Fórmula 1:

$$
\left|R_{i}-R_{j}\right| \geq Z_{\left(\frac{\alpha}{k(k-1)}\right)} \sqrt{\frac{N(N+1)}{12}\left(\frac{1}{n_{i}}+\frac{1}{n_{j}}\right)}
$$

Sendo:

Ri: a média dos postos da empresa i;

Rj: a média dos postos da empresa $\mathrm{j}$;

k: o número de sub-amostras;

$\mathrm{N}$ : o número de observações;

$Z_{\left(\frac{\alpha}{k((k-1)}\right)}$ : o valor da tabela normal $(Z)$, ao nível de significância $(\alpha)$, ajustado ao número de sub-amostras (k);

$\mathrm{n}_{\mathrm{i}}$ : o número de observações da empresa $\mathrm{i}$;

$\mathrm{n}_{\mathrm{j}}$ : o número de observações da empresa j;

Quando a diferença na soma dos postos entre duas empresas (parte esquerda da desigualdade na Fórmula (1)) é maior que a estatística calculada (parte direita da desigualdade na Fórmula (1)), elas são diferentes, utilizando $\alpha=5 \%$. Os dados das diferenças entre as somas dos postos (comparativo todas por todas) estão representadas no Apêndice A. O próximo tópico apresenta os resultados obtidos.

\section{Resultados}

Este tópico tem por finalidade apresentar os dados e resultados alcançados ao longo do estudo. As análises foram realizadas a partir dos indicadores de lucratividade e rentabilidade, utilizando-se do índice ROA, margem bruta, da margem EBITDA e da margem líquida, em 17 empresas do segmento de edificações listadas na Bolsa de Valores B3, em 22 trimestres, do primeiro trimestre de 2012 ao $2^{\circ}$ trimestre de 2017.

As informações apresentadas nos tópicos 4.1 e 4.2 foram organizadas da seguinte forma: estatísticas descritivas, por empresa, ordenada da maior para menor média. No tópico 4.3 são demonstrados os resultados do teste de Kruskal Wallis para analisar se os dados destas empresas provêm de uma mesma população ou se podem ser considerados diferentes.

\subsection{Análise da rentabilidade}

Para este tópico, foi utilizado o índice ROA, com o intuito de medir o grau da rentabilidade sobre o ativo. $\mathrm{O}$ indicador ROA representa a capacidade de uma empresa em gerar lucro com os ativos que possui, fornecendo uma visão de quão eficiente é a gestão do negócio na utilização do total de recursos disponíveis, para gerar ganhos.

Pelos resultados expostos, percebe-se que as empresas que obtiveram as piores médias foram a PDG REALT, CR2 e a JOAO FORTES. Destaca-se a PDG REALT que apresentou uma grande diferença entre média e mediana, o que significa que há maiores resultados em nível inferior à mediana, baixando a média, comprovado pela variabilidade, consonante com alto desvio padrão.

Importante ressaltar as maiores médias, nas quais foram a CONST A LIND, EZTEC e MRV. CONST A LIND, com a maior média, porém com o segundo maior desvio padrão da amostra, isto é, indica ser uma empresa instável por apresentar maiores variações em relação à 
média dos dados. Já a MRV é a terceira melhor média e possui o quarto menor desvio padrão, com CV de 0,6777, indicativo de maior estabilidade no desempenho entre os trimestres.

Tabela 1 - Estatística descritiva por empresa - ROA

\begin{tabular}{lcccccc}
\hline \multicolumn{1}{c}{ Empresas } & Média & Mediana & Desvio padrão & CV & Máximo & Mínimo \\
\hline CONST A LIND & 0,0669 & 0,0549 & 0,0704 & 1,0515 & 0,2833 & $-0,0492$ \\
EZTEC & 0,0348 & 0,0375 & 0,0161 & 0,4625 & 0,0674 & 0,0065 \\
MRV & 0,0153 & 0,0131 & 0,0104 & 0,6777 & 0,0517 & 0,0073 \\
DIRECIONAL & 0,0109 & 0,0150 & 0,0099 & 0,9076 & 0,0242 & $-0,0162$ \\
EVEN & 0,0109 & 0,0118 & 0,0130 & 1,1935 & 0,0505 & $-0,0160$ \\
CYRELA REALT & 0,0107 & 0,0123 & 0,0072 & 0,6658 & 0,0231 & $-0,0118$ \\
HELBOR & 0,0073 & 0,0083 & 0,0144 & 1,9579 & 0,0282 & $-0,0183$ \\
TRISUL & 0,0059 & 0,0056 & 0,0040 & 0,6787 & 0,0119 & $-0,0026$ \\
JHSF PART & 0,0044 & 0,0026 & 0,0162 & 3,6577 & 0,0512 & $-0,0433$ \\
RODOBENS & 0,0026 & 0,0078 & 0,0145 & 5,5527 & 0,0258 & $-0,0357$ \\
TENDA & $-0,0029$ & $-0,0042$ & 0,0114 & 3,9422 & 0,0125 & $-0,0289$ \\
TECNISA & $-0,0035$ & 0,0052 & 0,0275 & 7,8359 & 0,0441 & $-0,0812$ \\
GAFISA & $-0,0066$ & $-0,0008$ & 0,0330 & 5,0184 & 0,1091 & $-0,0601$ \\
ROSSI RESID & $-0,0171$ & $-0,0191$ & 0,0192 & 1,1265 & 0,0083 & $-0,0534$ \\
JOAO FORTES & $-0,0177$ & $-0,0127$ & 0,0227 & 1,2843 & 0,0205 & $-0,0764$ \\
CR2 & $-0,0213$ & $-0,0077$ & 0,0445 & 2,0849 & 0,0079 & $-0,2082$ \\
PDG REALT & $-0,0686$ & $-0,0149$ & 0,1241 & 1,8087 & 0,0058 & $-0,5463$ \\
\hline FOnI
\end{tabular}

Fonte: dados da pesquisa.

Ainda, pelo coeficiente de variação as empresas RODOBENS e TECNISA, apresentam as maiores variações em relação à média, respectivamente 6 vezes e 8 vezes. Tais empresas demonstram a maior volatilidade da amostra, em outras palavras, a valores dispersos do comportamento médio.

Por fim, ao analisar os dados das médias, é possível perceber que há proximidade ao zero, em que a diferença entre o maior e o menor valor é de 13,55 pontos percentuais (p.p). Isso é bastante reduzido entre os penúltimos lugares (CR2 e EZTEC), com diferença de 5,61 p.p., sinais de maior semelhança entre os resultados das empresas, reduzindo a utilidade da informação para o investidor.

\subsection{Análise de lucratividade}

Para este tópico, foram utilizadas a margem bruta, a margem EBITDA e a margem líquida, com o intuito de medir o grau da lucratividade do segmento.

\subsubsection{Análise da Margem Bruta}

A margem bruta representa quanto a empresa obtém de retorno das vendas líquidas, descontando apenas os custos da mercadoria vendida e serviços prestados. Quanto maior a margem, maior a lucratividade das vendas, isto é, maior a possibilidade de gerar resultado líquido positivo, após suportar as despesas de vendas, administrativas e resultado financeiro.

Tal como no tópico anterior, os dados foram apresentados por empresa, com destaque para a média e o desvio padrão e a diferença entre a média e a mediana.

De acordo com a Tabela 2, as três maiores médias da amostra pertencem as empresas EZTEC, CONST A LIND e JHSF PART, todas apresentando baixa volatilidade, em razão da pequena dispersão de dados em relação à média e variabilidade baixa. Importante destacar a EZTEC que além de obter a melhor média da amostra, ainda demonstra que o seu desvio é apenas de 0,07 vezes o comportamento médio. 
Tabela 2 - Estatística descritiva por empresa - MB

\begin{tabular}{lcccccc}
\hline \multicolumn{1}{c}{ Empresas } & Média & Mediana & Desvio padrão & CV & Máximo & Mínimo \\
\hline EZTEC & 0,5062 & 0,5050 & 0,0374 & 0,0740 & 0,5751 & 0,4340 \\
CONST A LIND & 0,4549 & 0,4830 & 0,0808 & 0,1775 & 0,5608 & 0,2952 \\
JHSF PART & 0,4526 & 0,4660 & 0,0730 & 0,1613 & 0,5824 & 0,2170 \\
CYRELA REALT & 0,3258 & 0,3271 & 0,0272 & 0,0836 & 0,3961 & 0,2672 \\
CR2 & 0,3016 & 0,2762 & 0,2136 & 0,7083 & 0,9654 & $-0,0448$ \\
MRV & 0,2953 & 0,2918 & 0,0265 & 0,0898 & 0,3398 & 0,2611 \\
TRISUL & 0,2835 & 0,2777 & 0,0426 & 0,1503 & 0,3599 & 0,1958 \\
EVEN & 0,2422 & 0,2608 & 0,0568 & 0,2345 & 0,3205 & 0,0873 \\
RODOBENS & 0,2343 & 0,2842 & 0,1375 & 0,5870 & 0,3893 & $-0,1619$ \\
HELBOR & 0,2247 & 0,2819 & 0,1430 & 0,6366 & 0,3627 & $-0,1295$ \\
TENDA & 0,2101 & 0,2586 & 0,1191 & 0,5672 & 0,3361 & $-0,0686$ \\
DIRECIONAL & 0,1984 & 0,2209 & 0,0861 & 0,4340 & 0,2784 & $-0,1003$ \\
GAFISA & 0,1543 & 0,2490 & 0,4674 & 3,0296 & 1,5717 & $-0,9521$ \\
ROSSI RESID & 0,0931 & 0,1547 & 0,1559 & 1,6738 & 0,3073 & $-0,2750$ \\
JOAO FORTES & $-0,0949$ & 0,1056 & 0,4285 & 4,5146 & 0,2905 & $-1,2999$ \\
TECNISA & $-0,2975$ & 0,2160 & 2,0157 & 6,7745 & 0,3362 & $-9,2655$ \\
PDG REALT & $-0,6915$ & 0,1638 & 1,5624 & 2,2595 & 0,3626 & $-4,5771$ \\
\hline
\end{tabular}

Fonte: dados da pesquisa.

Em relação às três piores médias da amostra, pertencem as empresas PDG REALT, TECNISA e JOAO FORTES, todas com alta volatilidade, em razão de obterem os maiores resultados de desvio padrão, variância e variabilidade. Ressaltando a empresa TECNISA que apresentou um desvio 6 vezes maior que a média e a maior variabilidade da amostra. Sendo a primeira linha de resultado na DR das empresas, níveis baixos deste indicador e, especialmente, negativos, representam maiores riscos operacionais destas empresas em relação às demais.

\subsubsection{Análise da Margem EBITDA}

Pelo indicador de lucratividade Margem EBITDA é possível medir o quanto a empresa gera de recursos apenas em suas atividades operacionais, sem levar em consideração os efeitos financeiros e impostos sobre o resultado. Assim, pode ser utilizado para comparar as empresas quanto à eficiência dentro de um determinado segmento do mercado, pelo foco no resultado de suas operações, antes dos efeitos de possíveis planejamentos tributários e da estrutura de capital. Além disso, a variação do indicador de um ano para o outro mostra aos investidores, se uma empresa conseguiu ser mais eficiente ou aumentar sua produtividade. Os dados são demonstrados na Tabela 3 por empresa, com destaque para a diferenciação da média para mediana, desvio padrão e variabilidade entre valores.

Destacam-se com maior distanciamento entre média e mediana, maiores desvios padrões e maiores variabilidades as empresas PDG REALT e TECNISA. Estas evidências demonstram que tais empresas possuem a maior volatilidade da amostra, com menor incidência de resultados próximos à média. A melhor média da amostra pertence à JHSF PART. No entanto, sua análise é prejudicada pelo alto $\mathrm{CV}$ e alta variabilidade, valor máximo obtido no quarto trimestre de 2013 e valor mínimo no quarto trimestre de 2016.

A empresa RODOBENS aparece com o maior CV da amostra, constituído por desvio padrão de aproximadamente quinze vezes maior que a média. Seguida da empresa GAFISA, com o segundo maior coeficiente de variação da amostra, sendo o desvio padrão pouco mais de seis vezes maior que a média. Apesar disto, suas diferenças entre média e mediana e variabilidade não foram significativas se comparadas a PDG REALT e a TECNISA. 
Tabela 3 - Estatística descritiva por empresa - MEBITDA

\begin{tabular}{lcccccc}
\hline \multicolumn{1}{c}{ Empresas } & Média & Mediana & Desvio padrão & CV & Máximo & Mínimo \\
\hline JHSF PART & 0,4179 & 0,3427 & 1,1998 & 2,8708 & 3,4447 & $-3,8214$ \\
EZTEC & 0,3223 & 0,3566 & 0,1035 & 0,3211 & 0,4279 & 0,0741 \\
CONST A LIND & 0,1988 & 0,2019 & 0,2170 & 1,0919 & 0,7261 & $-0,3860$ \\
CYRELA REALT & 0,1359 & 0,1496 & 0,0894 & 0,6577 & 0,2829 & $-0,2015$ \\
MRV & 0,1357 & 0,1344 & 0,0168 & 0,1241 & 0,1744 & 0,1070 \\
DIRECIONAL & 0,1003 & 0,1374 & 0,1059 & 1,0560 & 0,1933 & $-0,2352$ \\
TRISUL & 0,0943 & 0,0930 & 0,0304 & 0,3220 & 0,1469 & 0,0265 \\
HELBOR & 0,0891 & 0,1721 & 0,2019 & 2,2653 & 0,2740 & $-0,4005$ \\
EVEN & 0,0611 & 0,0913 & 0,1063 & 1,7399 & 0,1922 & $-0,1935$ \\
RODOBENS & 0,0163 & 0,1080 & 0,2464 & 15,1240 & 0,3447 & $-0,7057$ \\
TENDA & $-0,0383$ & $-0,0061$ & 0,1629 & 4,2476 & 0,1576 & $-0,4003$ \\
GAFISA & $-0,1039$ & 0,0199 & 0,6310 & 6,0703 & 1,8492 & $-1,4971$ \\
ROSSI RESID & $-0,2990$ & $-0,1866$ & 0,4308 & 1,4406 & 0,1464 & $-1,3745$ \\
JOAO FORTES & $-0,8396$ & $-0,1719$ & 1,7086 & 2,0350 & 0,1844 & $-7,5577$ \\
TECNISA & $-1,0497$ & 0,0467 & 4,3583 & 4,1522 & 1,2701 & $-20,3278$ \\
CR2 & $-1,0918$ & $-0,3446$ & 1,7936 & 1,6428 & 0,1381 & $-7,6302$ \\
PDG REALT & $-4,1474$ & $-0,1252$ & 8,4342 & 2,0336 & 0,1465 & $-31,8268$ \\
\hline
\end{tabular}

Fonte: dados da pesquisa.

As empresas MRV, TRISUL e EZTEC foram as que tiveram valores mais estáveis no período sendo que em todos os trimestres apresentaram MEBITDA positivo, com desvios padrões dentre os mais baixos e os menores coeficientes de variação da amostra, como também as menores variabilidades.

\subsubsection{Análise da Margem Líquida}

A margem líquida é utilizada para comparar a lucratividade das empresas após todos os efeitos sobre o desempenho da companhia. As estatísticas são apresentadas na Tabela 4.

Tabela 4 - Estatística descritiva por empresa - ML

\begin{tabular}{lcccccc}
\hline \multicolumn{1}{c}{ Empresas } & Média & Mediana & Desvio padrão & CV & Máximo & Mínimo \\
\hline EZTEC & 0,4611 & 0,4660 & 0,0987 & 0,2140 & 0,5885 & 0,2132 \\
CONST A LIND & 0,2385 & 0,2172 & 0,2335 & 0,9790 & 0,8630 & $-0,3534$ \\
MRV & 0,1381 & 0,1311 & 0,0613 & 0,4442 & 0,4028 & 0,0783 \\
CYRELA REALT & 0,1110 & 0,1261 & 0,0877 & 0,7904 & 0,2156 & $-0,2337$ \\
DIRECIONAL & 0,0808 & 0,1166 & 0,1125 & 1,3921 & 0,2125 & $-0,2608$ \\
EVEN & 0,0725 & 0,1044 & 0,0954 & 1,3149 & 0,2040 & $-0,1975$ \\
TRISUL & 0,0634 & 0,0623 & 0,0463 & 0,7303 & 0,1351 & $-0,0377$ \\
JHSF PART & 0,0532 & 0,0912 & 0,7783 & 14,6249 & 2,1641 & $-2,5863$ \\
HELBOR & 0,0201 & 0,1253 & 0,2649 & 13,1915 & 0,2829 & $-0,7927$ \\
RODOBENS & $-0,0080$ & 0,0877 & 0,2444 & 30,5040 & 0,2741 & $-0,7393$ \\
TENDA & $-0,0726$ & $-0,0493$ & 0,1578 & 2,1741 & 0,1463 & $-0,3878$ \\
GAFISA & $-0,2326$ & $-0,0116$ & 0,6845 & 2,9429 & 1,6413 & $-1,6682$ \\
ROSSI RESID & $-0,5785$ & $-0,5230$ & 0,6882 & 1,1896 & 0,0964 & $-2,4376$ \\
JOAO FORTES & $-0,9712$ & $-0,2185$ & 2,0774 & 2,1390 & 0,3593 & $-9,5570$ \\
TECNISA & $-1,1659$ & 0,0676 & 4,6760 & 4,0107 & 1,1400 & $-21,7748$ \\
CR2 & $-1,5151$ & $-0,3549$ & 2,8928 & 1,9094 & 0,4222 & $-13,2260$ \\
PDG REALT & $-5,2247$ & $-0,3329$ & 9,6491 & 1,8468 & 0,0549 & $-35,3539$ \\
\hline FOn
\end{tabular}

Fonte: dados da pesquisa.

A maior margem líquida média do período pertence a EZTEC. Ainda assim, ela é uma das empresas com a margem menos volátil da amostra, apresentando o menor coeficiente de variação. A CONST A LIND aparece com a segunda maior média, mas nota-se um comportamento inconstante de sua ML, com maior desvio padrão, coeficiente de variação e 
variabilidade se comparado a outras como a MRV e a TRISUL, nas quais os resultados são os que mais se aproximam ao comportamento médio.

Destacam-se três empresas com dispersões bem distantes do resto da amostra. São elas: PDG REALT, TECNISA e CR2. As três detêm o topo do ranking de maior distância entre média e mediana, maiores desvios padrões e maiores variabilidades. A CR2 em especial, apresentou um cenário curioso. Na Tabela 2 nota-se que sua MB média foi de 30,16\%, já sua ML ficou em -151,51\%. Este resultado foi único na amostra analisada. Através da consulta aos relatórios da empresa, nota-se um grande volume de despesas operacionais, sendo as mais impactantes provisões para perdas em recebíveis, despesas e provisões judiciais.

Não se pode deixar de citar a empresa RODOBENS, com um desvio padrão trinta vezes e meia maior do que a média o que representa que há valores bem dispersos da média da empresa. Após a análise descritiva dos dados, no próximo tópico são apresentados os testes para verificar se há diferenças significativas entre os resultados das empresas.

\subsection{Análise da Capacidade de Diferenciação dos Indicadores}

Considerando os dados analisados e a hipótese de pesquisa desenvolvida, este tópico apresenta dados para teste dessa, por meio do teste de Kruskal Wallis. A hipótese nula teórica do teste é " $\mathrm{H}_{0}$ : Os dados das empresas não diferem entre si" e, portanto, a hipótese alternativa é " $\mathrm{H}_{1}$ : Pelo menos duas empresas diferem entre si". Isso está alinhado à hipótese deste estudo: H1: Indicadores de desempenho financeiro de rentabilidade e lucratividade demonstram diferenças significativas entre empresas do mesmo segmento. A Tabela 5 apresenta os resultados qui-quadrado e p-valor por variável.

Tabela 5 - Resultados do teste Kruskal Wallis

\begin{tabular}{lcccc}
\hline Empresas / Média dos postos & ROA & MB & MEBITDA & ML \\
\hline CONST A LIND & 321,32 & 327,64 & 263,09 & 291,41 \\
CR2 & 86,61 & 193,68 & 64,64 & 78,09 \\
CYRELA REALT & 246,09 & 265,95 & 249,77 & 250,86 \\
DIRECIONAL & 247,14 & 123,50 & 224,36 & 229,09 \\
\multicolumn{1}{c}{ EVEN } & 235,48 & 159,18 & 186,82 & 213,00 \\
EZTEC & 326,18 & 347,82 & 329,41 & 354,86 \\
GAFISA & 118,23 & 143,68 & 129,00 & 119,64 \\
HELBOR & 213,25 & 179,82 & 232,41 & 218,91 \\
JHSF PART & 184,50 & 322,09 & 325,91 & 214,05 \\
JOAO FORTES & 91,27 & 64,50 & 86,91 & 93,14 \\
MRV & 267,27 & 223,05 & 241,00 & 262,14 \\
PDG REALT & 67,18 & 74,36 & 82,86 & 69,00 \\
RODOBENS & 186,05 & 186,09 & 190,95 & 192,86 \\
ROSSI RESID & 89,27 & 83,95 & 101,91 & 91,91 \\
TECNISA & 172,91 & 128,27 & 150,09 & 181,73 \\
TENDA & 139,73 & 157,36 & 134,82 & 135,18 \\
TRISUL & 195,02 & 206,55 & 193,55 & 191,64 \\
\hline H & $\mathbf{1 9 6 , 4 8}$ & $\mathbf{2 2 8 , 1 8}$ & $\mathbf{2 0 0 , 0 2}$ & $\mathbf{1 9 5 , 6 5}$ \\
p-valor & $\mathbf{0 , 0 0 0}$ & $\mathbf{0 , 0 0 0}$ & $\mathbf{0 , 0 0 0}$ & $\mathbf{0 , 0 0 0}$ \\
\hline
\end{tabular}

Fonte: dados da pesquisa.

$\mathrm{O}$ teste resultou, para todas as variáveis, $\mathrm{p}$-valor inferior $0,01 \%$, o que rejeita $\mathrm{H}_{0}$ do teste de Kruskal Wallis. Isto comprova que o teste é estatisticamente significativo e que pelo menos duas empresas diferem entre si ao nível de $0,01 \%$, nas quatro variáveis testadas. Com base nisso é possível afirmar que há evidências capazes de comprovar $\mathrm{H} 1$, ou seja, os indicadores de desempenho financeiro de rentabilidade e lucratividade demonstram diferenças significativas entre empresas do mesmo segmento econômico. 
No Quadro 4 é apresentado um ranking das empresas, pela média da soma de postos, por indicadores após o teste realizado. As companhias que se encontram mais próximas ao início ou fim da tabela são as que possuem maiores diferenças em relação às demais, enquanto o meio do quadro apresenta empresas mais semelhantes.

Quadro 4 - Ranking das empresas por indicadores após o teste de Kruskal Wallis

\begin{tabular}{|c|c|c|c|c|}
\hline Ranking & ROA & MB & MEBITDA & ML \\
\hline 1 & EZTEC & EZTEC & EZTEC & EZTEC \\
\hline 2 & CONST A LIND & CONST A LIND & JHSF PART & CONST A LIND \\
\hline 3 & MRV & JHSF PART & CONST A LIND & MRV \\
\hline 4 & DIRECIONAL & CYRELA REALT & CYRELA REALT & CYRELA REALT \\
\hline 5 & CYRELA REALT & MRV & MRV & DIRECIONAL \\
\hline 6 & EVEN & TRISUL & HELBOR & HELBOR \\
\hline 7 & HELBOR & CR2 & DIRECIONAL & JHSF PART \\
\hline 8 & TRISUL & RODOBENS & TRISUL & EVEN \\
\hline 9 & RODOBENS & HELBOR & RODOBENS & RODOBENS \\
\hline 10 & JHSF PART & EVEN & EVEN & TRISUL \\
\hline 11 & TECNISA & TENDA & TECNISA & TECNISA \\
\hline 12 & TENDA & GAFISA & TENDA & TENDA \\
\hline 13 & GAFISA & TECNISA & GAFISA & GAFISA \\
\hline 14 & JOAO FORTES & DIRECIONAL & ROSSI RESID & JOAO FORTES \\
\hline 15 & ROSSI RESID & ROSSI RESID & JOAO FORTES & ROSSI RESID \\
\hline 16 & CR2 & PDG REALT & PDG REALT & CR2 \\
\hline 17 & PDG REALT & JOAO FORTES & CR2 & PDG REALT \\
\hline
\end{tabular}

Fonte: dados da pesquisa.

A EZTEC apresentou maior diferenciação em todos os indicadores em relação às demais companhias. Por sua vez, CONST A LIND apresentou a segunda maior diferenciação perdendo somente para a JHSF PART no indicador MEBITDA. Na outra ponta, com as menores somas de postos, diferenciando-se das demais, a PDG REALT, aparecendo ao final do ranking em dois dos indicadores, seguida, das empresas JOAO FORTES e CR2.

Apesar de indicativo de diferenças significativas entre as companhias, se sabe que pelo menos uma empresa se diferencia de outra, não identificando quais são elas em cada variável. O procedimento de comparações múltiplas permite tal análise, utilizando a Fórmula 1. A estatística calculada resultou em 116,1. Logo, se a diferença na soma dos postos entre duas empresas for maior que 116,1, isto significa que há diferença estatisticamente significativa entre estas. Como tal estatística é calculada conforme as observações em cada teste, mudanças de amostra e resultariam em parâmetros diferentes. O mesmo número, 116,1, é utilizado para todas as variáveis pois a amostra (n) em cada uma delas é de mesmo tamanho.

$\mathrm{Na}$ Tabela 6 são apresentadas as quantidades de diferenças significativas de cada empresa, ao nível de $95 \%$ de confiança, através da contagem dessas, utilizando as tabelas por indicador do Apêndice A. Os dados apresentados no apêndice permitem a análise individual de uma empresa com cada uma das demais, com destaque para as diferenças entre elas.

O maior número de diferenças de uma empresa para com as outras de um único indicador seria 16. Do resultado da contagem, a empresa que apresentou o maior número de diferenças entre as demais foi a EZTEC com 12 diferenças no indicador Margem bruta, a qual já havia sido destaque na análise da Margem Bruta, no tópico 4.2.1.

Ainda, as empresas EZTEC e CONST A LIND foram as que apresentaram maior diferença entre as demais da amostra, as únicas com ao menos metade das observações com diferenças significativas, 42 e 32 respectivamente. Comparando tais dados com a Tabela 5, deve-se considerar que as diferenças ocorrem para nas extremidades, nas empresas de melhor e de pior desempenho em cada indicador, ou seja, as duas comparações devem ser realizadas 
em conjunto, o que pode ser realizado no modelo das tabelas do Apêndice A, em que as médias de postos são apresentadas e as diferenças estatisticamente significativas são destacadas.

Quando ampliado para análise das diferenças em mais de 40\% das comparações, 7 das 17 companhias apresentam tal nível. Na outra ponta da tabela, as empresas RODOBENS, TENDA e TECNISA apresentam menos de $20 \%$ das comparações com diferenças significativas.

Tabela 6 - Diferenças significativas por empresa por indicador

\begin{tabular}{lccccc}
\hline EMPRESA & ROA & MB & MEBTIDA & ML & \% de diferenças \\
\hline EZTEC & 9 & 12 & 9 & 12 & $66 \%$ \\
CONST A LIND & 9 & 11 & 6 & 6 & $50 \%$ \\
PDG REALT & 9 & 6 & 7 & 9 & $48 \%$ \\
CR2 & 7 & 5 & 9 & 8 & $45 \%$ \\
JOAO FORTES & 7 & 7 & 7 & 8 & $45 \%$ \\
JHSF PART & 3 & 11 & 9 & 5 & $44 \%$ \\
ROSSI RESID & 7 & 5 & 7 & 8 & $42 \%$ \\
CYRELA REALT & 5 & 6 & 5 & 5 & $33 \%$ \\
MRV & 6 & 4 & 4 & 6 & $31 \%$ \\
DIRECIONAL & 5 & 4 & 4 & 5 & $28 \%$ \\
GAFISA & 6 & 4 & 4 & 4 & $28 \%$ \\
EVEN & 5 & 3 & 3 & 5 & $25 \%$ \\
HELBOR & 4 & 3 & 4 & 5 & $25 \%$ \\
TRISUL & 3 & 5 & 3 & 2 & $20 \%$ \\
RODOBENS & 3 & 4 & 3 & 2 & $19 \%$ \\
TENDA & 3 & 3 & 3 & 3 & $19 \%$ \\
TECNISA & 2 & 4 & 2 & 1 & \\
Total & 93 & 97 & 89 & 94 & \\
$\%$ de diferenças & $34 \%$ & $36 \%$ & $33 \%$ & $35 \%$ & \\
$\%$ de não diferenças & $66 \%$ & $64 \%$ & $67 \%$ & $65 \%$ & \\
\hline
\end{tabular}

Fonte: dados da pesquisa.

$\mathrm{Na}$ análise por variável, o número máximo de diferenças que as empresas poderiam ter para um mesmo indicador seria $272(16 \times 17)$ e a contagem final de cada indicador ficou como segue: ROA 93, MB 97, MEBITDA 89 e ML 94 diferenças significativas entre as empresas. Pelos resultados não é possível afirmar que uma das variáveis se diferencia das demais, visto que oscilam de $33 \%$ a $36 \%$ das observações com diferenças significativas entre as amostras. Tanto os indicadores MB e MEBITDA, que refletem a performance operacional e, assim, teriam maior sensibilidade em relação ao desempenho dos gestores (LAMBERT, 2001), quanto os que contemplam os efeitos da estrutura de capital, por medirem o resultado considerando efeitos do custo do dessa, medidas de lucro líquido, parâmetro distribuição de dividendos, interesse dos investidores, são semelhantes em termos de volume de explicação.

Assim, a relevância e utilidade (KULVIWAT et al., 2004; CPC00, 2011) da informação contábil pode ser comprovada, mesmo a ressalva da análise ser restrita a empresas do mesmo segmento. Sendo medidas facilmente obtidas pelos investidores e demais interessados, devido, também à sua obrigatoriedade (PACE; BASSO; SILVA, 2003), há condições de proceder análises, inclusive trimestralmente, sobre as diferenças significativas entre o desempenho das companhias com reduzido custo informacional.

No entanto, é possível perceber a limitação das quatro variáveis, ao demonstrar diferenças com menos de $40 \%$ entre as empresas. Isso reforça a percepção sobre o cuidado nas análises de empresas de um mesmo segmento, sujeitas a efeitos semelhantes do ambiente, em linha com as abordagens contingenciais (LARWENCE; LORSCH, 1967; DONALDSON, 2001). As empresas com menores diferenças entre si são as que mais se assemelham a índices setoriais médios (DUARTE; LAMOUNIER, 2007) e, assim, poderiam ter suas análises 
individuais suprimidas, reduzindo custos dos esforços dos usuários para gerar informações individuais (KULVIWAT et al., 2004).

Assim, a análise das diferenças entre empresas é passo importante para identificar em quais situações os indicadores são relevantes, permitindo que investidores julguem melhor suas decisões, evitando vieses cognitivos (MACEDO; FONTES, 2009). Ainda, a metodologia apresentada não é complexa ao ponto de não ser utilizada por não especialistas, permitindo também que usuários não profissionais possam operá-la e elevar o volume de dados financeiros utilizados para julgamento (PENNINGTON; KELTON, 2016).

Com base nos resultados obtidos, percebe-se que foi possível identificar diferenças significativas entre empresas do segmento de edificações, listadas na B3, utilizando os indicadores de lucratividade e rentabilidade aqui analisados, o que deve ser realizado com parcimônia, visto que há mais semelhanças do que diferenças entre as companhias. As conclusões do estudo são apresentadas a seguir.

\section{Conclusão}

Em se tratando de mercado de capitais, os principais usuários da informação contábil são os investidores e os analistas financeiros. Assumindo o pressuposto de que a informação útil é aquela capaz de influenciar a decisão e que isso pode ser prejudicado à medida que as empresas se assemelham, pela redução da comparabilidade e diferenciação, esta pesquisa procurou identificar a capacidade dos indicadores de rentabilidade e lucratividade em produzir subsídios para investidores, por meio da diferenciação das empresas de um mesmo segmento de atuação. Em particular, foram utilizados dados trimestrais de companhias do segmento de edificações da B3.

Foram analisados quatro indicadores, pela estatística descritiva, seguido do teste para a hipótese desenvolvida, por meio do teste de Kruskal Wallis. Confirmada tal hipótese, é possível concluir que os indicadores de desempenho financeiro de rentabilidade e lucratividade demonstram diferenças significativas entre empresas do mesmo segmento. Tal passo remete à análise do volume dessas diferenças, comparando as companhias. Por essa, foi possível identificar empresas que remetem a análises individuais e as que podem assemelhar-se ao comportamento médio do segmento, visto que, combinadas entre si, apresentam similaridades de desempenho.

Entretanto, restrições devem ser observadas, pela capacidade de diferenciar empresas em menos da metade das combinações, para todos os indicadores. Assim, apesar de apresentar diferenças estatisticamente significativas em todos os indicadores, o procedimento de comparações múltiplas é etapa adequada aos analistas e investidores antes da decisão do uso, ou não, de um indicador para comparar empresas e julgar o desempenho, bem como sobre a extensão da aplicabilidade de tal processo. Agindo dessa forma, os usuários de tais técnicas poderão julgar as empresas que apresentam maior número de diferenças e, caso tenham interesse em acompanhar e analisar as demais companhias, terão custos adicionais para obter, tratar e analisar informações dessas.

Por outro lado, poderão optar por analisar tal grupo de empresas por índices médios do setor, considerada a maior similaridade entre elas. Esta decisão, no entanto, precisa ser seguida de nova análise, que pode assemelhar-se ao roteiro seguido nesta pesquisa, além de revisar literatura existente sobre tal abordagem, a exemplo de Duarte e Lamounier (2007).

Com isso, a pesquisa contribui para a literatura sobre indicadores da análise das demonstrações contábeis, discutindo seu poder de explicação para uso em análise de empresas, incluindo aquelas listadas no mercado de capitais. Ainda, ao diferenciar as empresas por meio da técnica de comparações múltiplas apresenta subsídios para analistas financeiros e investidores utilizarem nas suas atividades, bem como para pesquisadores que procurem 
analisar o uso e a relevância da informação contábil no ambiente das empresas, especialmente aquelas de capital aberto. Contribuição adicional para as escolhas de informações diante do número reduzido de dados financeiros que investidores não profissionais utilizam (PENNINGTON; KELTON, 2016), procurando reduzir os efeitos dos vieses de decisão, mesmo em investidores profissionais (MACEDO; FONTES, 2009) e os custos de obter, tratar e analisar informações.

As limitações da pesquisa, especialmente sobre a utilização de uma técnica e da amostra levam à sugestão de novos estudos. Inicialmente pela análise multisetorial, o que poderia identificar grupos de empresas que se assemelham e se diferenciam nos desempenhos de mesmos períodos. Ainda, a ampliação de indicadores poderá propor a discussão sobre a combinação de múltiplos fatores, incluindo medidas financeiras e não financeiras.

\section{Referências}

AKERLOFF, G. The market for "lemons": quality uncertainty and the market mechanism. The Quarterly Journal of Economics, v. 84 n. 3. p. 488-500, 1970. https://doi.org/10.2307/1879431

ALMEIDA, L. S. F. de; VIEIRA NETO, J.; SALLES, M. T.; SOARES, C. A. P.; ESTEVES, Y. de O. Análise comparativa entre o EVA ${ }^{\circledR}$ e os indicadores financeiros (contábeis) tradicionais de empresas da construção civil brasileira: um estudo documental. Revista Gestão \& Produção, v. 23, n. 4, p. 733-756, 2016. http://dx.doi.org/10.1590/0104-530x172215

BIDDLE, G. C.; HILARY, G.; VERDI, R. S. How does financial reporting quality relate to investment efficiency? Journal of Accounting and Economics, v. 48, n. 2-3, p. 112-131, 2009. https://doi.org/10.1016/j.jacceco.2009.09.001

BORTOLUZZI, S. C.; ENSSLIN, S. R.; LYRIO, M. V. L.; ENSSLIN, L. Avaliação de desempenho econômico-financeiro: uma proposta de integração de indicadores contábeis tradicionais por meio da metodologia multicritério de apoio à decisão construtivista (MCDAC). Revista Alcance - Eletrônica, v. 18, n. 2, p. 200-218, 2011. http://dx.doi.org/10.14210/alcance.v18n2.p200-218

BURNS, T.; STALKER, G. M. The management of innovation, 1961. In: TOSI, H. Theories of Organization. Londres: Sage Publications, 2009.

BUSHMAN, R. M.; SMITH, A. J. Financial accounting information and corporate governance. Journal of Accounting and Economics, v. 32, n. 1-3, p. 237-333, 2001. https://doi.org/10.1016/S0165-4101(01)00027-1

CHILD, J. Organizational structure, environment and performance: the role of strategic choice. Social Science Collection, v. 6, n. 1, p. 1-22, 1972.

https://doi.org/10.1177\%2F003803857200600101

COMITÊ DE PRONUNCIAMENTOS CONTÁBEIS, CPC 00. Estrutura Conceitual para Elaboração e Divulgação de Relatório Contábil-Financeiro.Brasília, 2011. Disponível em: http://www.cpc.org.br/CPC/DocumentosEmitidos/Pronunciamentos/Pronunciamento? $\mathrm{Id}=80$. Acesso em: 17 nov. 2017. 
CONLISK, J. Why bounded rationality? Journal of Economic Literature. v. 34, v. 2, p. 669-700, 1996.

DONALDSON, L. The contingency theory of organizations. Sage Publications, 2001.

DUARTE, H. C. F.; LAMOUNIER, W. M. Análise financeira de empresas da construção civil por comparação com índices-padrão. Enfoque: Reflexão Contábil, v. 26, n. 2, p. 9-23, 2007. http://dx.doi.org/10.4025/enfoque.v26i2.4786

EISENHARDT, K. M. Agency theory: an assessment and review. The Academy of Management Review, v. 14, n. 1, p. 57-74, 1989. http://doi.org/10.2307/258191

ELING, M.; JIA, R. Business failure, efficiency, and volatility: evidence from the European insurance industry. International Review of Financial Analysis, v. 59, p. 58-76, 2018. https://doi.org/10.1016/j.irfa.2018.07.007

GALDI, F. C. Estratégias de investimento em ações baseadas na análise de demonstrações contábeis: é possível prever sucesso? 2008. 129 f. Tese (Doutorado em Ciências Contábeis) - Programa de Pós-Graduação em Ciências Contábeis da Universidade de São Paulo, São Paulo, 2008.

GUAY, W. Discussion of value investing: the use of historical financial statement information to separate winners from losers. Journal of Accounting Research, v. 38, p. 4351, 2000. http://doi.org/10.2307/2672907

JENSEN, M. C.; MECKLING, W. H. Theory of the firm: managerial behavior, agency costs and ownership structure. Journal of Financial Economics, v. 3, n. 4, p. 305-360, 1976. https://doi.org/10.1016/0304-405X(76)90026-X

KITZBERGER, H.; PADOVEZE, C. L. Integração do Modelo Fleuriet com a abordagem tradicional de análise das demonstrações contábeis. Revista Pensar Contábil, v. 6, n. 23, 2004.

KOTHARI, S. P. Capital markets research in accounting. Journal of Accounting and Economics, n. 31, p. 105-231, 2001. https://doi.org/10.1016/S0165-4101(01)00030-1

KULVIWAT, S.; GUO, C.; ENGCHANIL, N. Determinants of online information search: a critical review and assessment. Internet Research, v. 14, n. 3, p. 245-253, 2004. https://doi.org/10.1108/10662240410542670

LAMBERT, R. A. Agency theory and management accounting. In: CHAPMAN, C. S.; HOPWOOD, A. G.; SHIELDS, M. D. Handbook of management accounting research. v. 1. Amsterdã, Holanda: Elsevier, 2007. pp. 247-268.

LARWENCE, P. R.; LORSCH, J. W. Differentiation and integration in complex organizations. Administrative Science Quarterly, v. 12, n. 1, p. 1-47, 1967. http://doi.org/10.2307/2391211

LEUZ, C.; VERRECCHIA, R. E. The economic consequences of increased disclosure. Journal of Accounting Research, v. 38, p. 91-124, 2000. http://doi.org/10.2307/2672910 
MACEDO, M. A. da S.; FONTES, P. F. da S. Análise do comportamento decisório de analistas contábil-financeiros: um estudo com base na Teoria da Racionalidade Limitada.

Revista Contemporânea de Contabilidade, v. 1, n. 11, p. 159-186, 2009.

https://doi.org/10.5007/2175-8069.2009v6n11p159

MARTINEZ, A. L. Do corporate governance special listing segments and auditing curb real and accrual-based earnings management? Evidence from Brazil. Revista Universo Contábil, v. 7, n. 4, p. 98-117, 2011. http://doi.org/10.4270/RUC.2011433

MILTERSTEINER, M. da R. A validade estatística do uso de índices fundamentalistas no mercado de capitais brasileiro: um estudo aplicado ao setor bancário. $2003.85 \mathrm{f}$.

Dissertação (Mestrado em Engenharia de Produção) Programa de Pós Graduação em Engenharia de Produção da Universidade Federal de Santa Catarina, Florianópolis, 2003

OLSON, D.; MOSSMAN, C. Neural network forecasts of Canadian stock returns using accounting ratios. International Journal of Forecasting, v. 19, n. 3, p. 453-465, 2003. https://doi.org/10.1016/S0169-2070(02)00058-4

PACE, E. S. U; BASSO, L. F. C.; SILVA, M. A. da. Indicadores de desempenho como direcionadores de valor. Revista de Administração Contemporânea, v. 7, n. 1, p. 37-65, 2003. http://dx.doi.org/10.1590/S1415-65552003000100003

PENNINGTON, R. R.; KELTON, A. S. How much is enough? An investigation of nonprofessional investors information search and stopping rule use. International Journal of Accounting Information Systems, v. 21, p. 47-62, 2016.

https://doi.org/10.1016/j.accinf.2016.04.003

PIOTROSKI, J. D. Value investing: the use of historical financial statement information to separate winners from losers. Journal of Accounting Research, v. 38, p. 1-41, 2000. http://doi.org/10.2307/2672906

SIEGEL, S. Estatisticanão-paramétrica: para as ciências do comportamento. 2. ed. São Paulo: Artmed, 2006.

SHEA, P. Red herrings and revelations: does learning about a new variable worsen forecasts? Economic Modelling, v. 49, p. 395-406, 2015. https://doi.org/10.1016/j.econmod.2015.05.012

SILVA, C. M. da; ALMEIDA, E. G. de A. Avaliação comparativa do modelo dinâmico versus modelo tradicional na análise das demonstrações financeiras: um estudo aplicado na Kroton Educacional S.A. Revista de Auditoria Governança e Contabilidade, v. 6, n. 22, p. 31-47, 2018.

SILVA, J. P. D. Análise financeira das empresas, 12. ed. São Paulo: Atlas, 2013.

SILVA, M. P. da; COUTO, C. H. da M.; CARDOSO, A. A. B. Análise das demonstrações contábeis como ferramenta de suporte à gestão financeira. Revista Brasileira de Gestão e Engenharia, n. 13, p. 23-45, 2016. 
SILVA, T. A. da; SANCHES, S. L. R.; IGARASHI, D. C. C. Contingências passivas e teoria dos prospectos: análise dos efeitos em indicadores financeiros de empresas de construção civil e construção pesada. Revista Evidenciação Contábil \& Finanças, v. 7, n. 1, p. 39-57, 2019. https://doi.org/10.22478/ufpb.2318-1001.0v0n0.35534

SILVEIRA, A. M.; LEAL, R. P. C.; BARROS, L. A. B. C.; CARVALHAL-DA-SILVA, A. L. Evolution and determinants of firm-level corporate governance quality in Brazil. Revista de Administração, v. 44, n. 3, p. 173-189, 2009.

TAVARES, A. de L.; SILVA, C. A. T. A análise financeira fundamentalista na previsão de melhores e piores alternativas de investimento. Revista Universo Contábil, v. 8, n. 1, p. 3752, 2012. http://doi.org/10.4270/RUC.2012103

\section{APÊNDICE A}

Tabela 7 - Comparações múltiplas entre empresas - ROA

\begin{tabular}{|c|c|c|c|c|c|c|c|c|c|c|c|c|c|c|c|c|c|c|}
\hline ESA & CóD & 1 & 2 & 3 & 4 & 5 & 6 & 7 & 8 & 9 & 10 & 11 & 12 & 13 & 14 & 15 & 16 & 17 \\
\hline$T$ & 1 & 0 & 234,7 & 75,2 & 74,2 & 85,8 & 4,9 & 3,1 & 10 & 136,8 & 230,0 & , 0 & & & 232,0 & 148,4 & & 1 \\
\hline & 2 & & 0,0 & 159,5 & 160,5 & & & & & &, 7 & & & & & & & \\
\hline-1 & 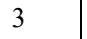 & 75,2 & 159,5 & 0,0 & 1,0 & 10,6 & 80,1 & 127,9 & & 61,6 & 154,8 & 21,2 & 178,9 & 0,0 & 156,8 & 73,2 & & 51,1 \\
\hline & 4 & 2 & & 1,0 & & 11,1 & & & & & & 2 & & & & 74,2 & & 52,1 \\
\hline & 5 & & & 10,6 & & 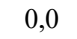 & & & & & & & & & & 6 & & 40,5 \\
\hline ZT & 6 & 4,9 & 239,6 & 80,1 & 79,0 & 90,7 & 0,0 & 208,0 & 112,9 & 141,7 & 234,9 & 58,9 & 259,0 & 140,1 & 236,9 & 153,3 & 186,5 & 131,2 \\
\hline & 7 & 3,1 &, 6 & 127,9 & 128,9 & 117,3 & 208,0 & 0 & 95,0 & & 27,0 & 149,0 & 51,0 &, 8 & 0 & & & \\
\hline & 8 & & & & 33,9 & & & & & & & & & & & & & \\
\hline & 9 & 8 & & 61,6 & 62,6 & 51,0 & & & 2 & & 93,2 & 82,8 & 117,3 & 1.5 & 95,2 & 11,6 & 8 & 10,5 \\
\hline & & 0,0 & 4,7 & 154,8 & 155,9 & 144,2 & & 27,0 & 12 & 93 & 0,0 & 176,0 & 24,1 & , 8 & 2,0 & ,6 & 48,5 & 103,8 \\
\hline & & &, 7 & & & & & & & & 176,0 & & 200,1 & & 178,0 & ,4 & & \\
\hline & & $T_{1}$ & & 178,9 & 180,0 & 168,3 & & & 146,1 & 11 & 24,1 & 200,1 & & 118,9 & ,1 & & 72,5 & 127,8 \\
\hline & 1 & 5,3 & 99,4 & 60,0 & 61,1 & 49,4 & 1 & 8 & 2 & & 94,8 & 81,2 & 118,9 & 0,0 & 96,8 &, 1 & 6,3 & 9,0 \\
\hline & & & 2,7 & 156,8 & 157,9 & 146,2 & & & 124,0 & & 2,0 & 178,0 & & & & &, 5 & 105,8 \\
\hline & & & 86,3 & 73,2 & & & & & & & 81,6 & & & & & 0,0 & 3,2 & 22,1 \\
\hline & 16 & 1,6 & 53,1 & 106,4 & 107,4 & 95,8 & & 21,5 & & 4 & 48,5 & 127,5 & 72,5 & 46,3 & 5 & 33,2 & 0 & 55,3 \\
\hline IN14 & 17 & 126,3 & 108,4 & 51,1 & 52,1 & 40,5 & 131,2 & 76,8 & 18,2 & 10,5 & 103,8 & 72,3 & 127,8 & 9,0 & 105,8 & 22,1 & 55,3 & 0,0 \\
\hline N. de diferenças & & 10 & 7 & 5 & 5 & 5 & 10 & 6 & 4 & 3 & 7 & 6 & 10 & 3 & 7 & 2 & 3 & 3 \\
\hline
\end{tabular}

Fonte: dados da pesquisa.

Tabela 8 - Comparações múltiplas entre empresas - Margem Bruta

\begin{tabular}{|c|c|c|c|c|c|c|c|c|c|c|c|c|c|c|c|c|c|c|}
\hline EMPRESA & CÓD & & 2 & 3 & 4 & 5 & 6 & 7 & 8 & 9 & 10 & 11 & 12 & 13 & 14 & 15 & 16 & 17 \\
\hline CONST A LIND & 1 & 0,0 & 34,0 & 61,7 & 4,1 & 168,5 & 20,2 & 184,0 & 147,8 & 5,5 & 263,1 & 104,6 & 253,3 & 141,5 & 243,7 & 199,4 & 170,3 & 121 , \\
\hline R2 & 2 & 134,0 & 0,0 & 72,3 & 70,2 & 4,5 & 154,1 & 50,0 & 13,9 & 128,4 & 129,2 & 29,4 & 119,3 & 7,6 & 109,7 & 65,4 & 36,3 & 12,9 \\
\hline YRELA REALT & 3 & 61,7 & 72,3 & 0,0 & 142,5 & 106,8 & 81,9 & 122,3 & 86,1 & 56,1 & 201,5 & 42,9 & 191,6 & 79,9 & 182,0 & 137,7 & 108,6 & 59,4 \\
\hline DIRECIONAL & 4 & 204,1 & 70,2 & 142,5 & 0,0 & 35,7 & 224,3 & 20,2 & 56,3 & 198,6 & 59,0 & 99,5 & 49,1 & 62,6 & 39,5 & 4,8 & 33,9 & 83,0 \\
\hline EVEN & 5 & 168,5 & 34,5 & 106,8 & 35,7 & 0,0 & 188,6 & 15,5 & 20,6 & 162,9 & 94,7 & 63,9 & 84,8 & 26,9 & 75,2 & 30,9 & 1,8 & 47,4 \\
\hline EZTEC & 6 & 20,2 & 154,1 & 81,9 & 224,3 & 188,6 & 0,0 & 204,1 & 168,0 & 25,7 & 283,3 & 124,8 & 273,5 & 161,7 & 263,9 & 219,5 & 190,5 & 141,3 \\
\hline $\mathrm{AF}$ & 7 & 184,0 & 50,0 & 122,3 & 20,2 & 15,5 & 204,1 & 0,0 & 36,1 & 178,4 & 79,2 & 79,4 & 69,3 & 42,4 & 59,7 & 15,4 & 13,7 & 62,9 \\
\hline HELF & 8 & 147,8 & 13,9 & 86,1 & 56,3 & 20,6 & 168,0 & 36,1 & 0,0 & 142,3 & 115,3 & 43,2 & 105,5 & 6,3 & 95,9 & 51,5 & 22,5 & 26,7 \\
\hline ISF & 9 & 5,5 & 128,4 & 56,1 & 198,6 & 162,9 & 25,7 & 178,4 & 142,3 & 0,0 & 257,6 & 99,0 & 247,7 & 136,0 & 238,1 & 193,8 & 164,7 & 115,5 \\
\hline U. & 10 & 263,1 & 129,2 & 201,5 & 59,0 & 94,7 & 283,3 & 79,2 & 115,3 & 257,6 & 0,0 & 158,5 & 9,9 & 121,6 & 19,5 & 63,8 & 92,9 & 142,0 \\
\hline ARV & 11 & 4.6 & 29,4 & 42,9 & 99,5 & 63,9 & 124,8 & 79,4 & 43,2 & 99,0 & 158,5 & 0,0 & 148,7 & 37,0 & 139,1 & 94,8 & 65,7 & 16,5 \\
\hline DG & 12 & 253,3 & 119,3 & 191,6 & 49,1 & 84,8 & 273,5 & 69,3 & 105,5 & 247,7 & 9,9 & 148,7 & 0,0 & 111,7 & 9,6 & 53,9 & 83,0 & 132,2 \\
\hline $\mathrm{OD}$ & 313 & 141,5 & 7,6 & 79,9 & 62,6 & 26,9 & 161,7 & 42,4 & 6,3 & 136,0 & 121,6 & 37,0 & 111,7 & 0,0 & 102,1 & 57,8 & 28,7 & 20,5 \\
\hline ROSSI RESID & 14 & 243,7 & 109,7 & 182,0 & 39,5 & 75,2 & 263,9 & 59,7 & 95,9 & 238,1 & 19,5 & 139,1 & 9,6 & 102,1 & 0,0 & 44,3 & 73,4 & 122,6 \\
\hline TECNISA & 15 & 199,4 & 65,4 & 137,7 & 4,8 & 30,9 & 219,5 & 15,4 & 51,5 & 193,8 & 63,8 & 94,8 & 53,9 & 57,8 & 44,3 & 0,0 & 29,1 & 78,3 \\
\hline TENDA & 16 & 170,3 & 36,3 & 108,6 & 33,9 & 1,8 & 190,5 & 13,7 & 22,5 & 164,7 & 92,9 & 65,7 & 83,0 & 28,7 & 73,4 & 29,1 & 0,0 & 49,2 \\
\hline TRISUL & 17 & 121,1 & 12,9 & 59,4 & 83,0 & 47,4 & 141,3 & 62,9 & 26,7 & 115,5 & 142,0 & 16,5 & 132,2 & 20,5 & 122,6 & 78,3 & 49,2 & 0,0 \\
\hline N. de diferenças & & 12 & 5 & 6 & 4 & 3 & 13 & 4 & 3 & 11 & 8 & 4 & 7 & 4 & 6 & 4 & 3 & 5 \\
\hline
\end{tabular}

Fonte: dados da pesquisa. 
Tabela 9 - Comparações múltiplas entre empresas - Margem EBITDA

\begin{tabular}{|c|c|c|c|c|c|c|c|c|c|c|c|c|c|c|c|c|c|c|}
\hline EMPRESA & CÓD & 1 & 2 & 3 & 4 & 5 & 6 & 7 & 8 & 9 & 10 & 11 & 12 & 13 & 14 & 15 & 16 & 17 \\
\hline CONST A LIND & 1 & 0,0 & 198,5 & 13,3 & 38,7 & 76,3 & 66,3 & 134,1 & 30,7 & 62,8 & 176,2 & 22,1 & 180,2 & 72,1 & 161,2 & 113,0 & 128,3 & 69,5 \\
\hline $\mathrm{CR} 2$ & 2 & 198,5 & 0,0 & 185,1 & 159,7 & 122,2 & 264,8 & 64,4 & 167,8 & 261,3 & 22,3 & 176,4 & 18,2 & 126,3 & 37,3 & 85,5 & 70,2 & 128,9 \\
\hline CYRELA REALT & 3 & 13,3 & 185,1 & 0,0 & 25,4 & 63,0 & 79,6 & 120,8 & 17,4 & 76,1 & 162,9 & 8,8 & 166,9 & 58,8 & 147,9 & 99,7 & 115,0 & 56,2 \\
\hline DIRECIONAL & 4 & 38,7 & 159,7 & 25,4 & 0,0 & 37,5 & 105,0 & 95,4 & 8,0 & 101,5 & 137,5 & 16,6 & 141,5 & 33,4 & 122,5 & 74,3 & 89,5 & 30,8 \\
\hline EVEN & 5 & 76,3 & 122,2 & 63,0 & 37,5 & 0,0 & 142,6 & 57,8 & 45,6 & 139,1 & 99,9 & 54,2 & 104,0 & 4,1 & 84,9 & 36,7 & 52,0 & 6,7 \\
\hline EZTEC & 6 & 66,3 & 264,8 & 79,6 & 105,0 & 142,6 & 0,0 & 200,4 & 97,0 & 3,5 & 242,5 & 88,4 & 246,5 & 138,5 & 227,5 & 179,3 & 194,6 & 135,9 \\
\hline GAFISA & 7 & 134,1 & 64,4 & 120,8 & 95,4 & 57,8 & 200,4 & 0,0 & 103,4 & 196,9 & 42,1 & 112,0 & 46,1 & 62,0 & 27,1 & 21,1 & 5,8 & 64,5 \\
\hline HELB & 8 & 30,7 & 167,8 & 17,4 & 8,0 & 45,6 & 97,0 & 103,4 & 0,0 & 93,5 & 145,5 & 8,6 & 149,5 & 41,5 & 130,5 & 82,3 & 97,6 & 38,9 \\
\hline JHSF & , & 62,8 & 261,3 & 76,1 & 101,5 & 139,1 & 3,5 & 196,9 & 93,5 & 0,0 & 239,0 & 84,9 & 243,0 & 135,0 & 224,0 & 175,8 & 191,1 & 132,4 \\
\hline $\mathrm{A}$ & 10 & 76,2 & 22,3 & 162,9 & 137,5 & 99,9 & 242,5 & 42,1 & 145,5 & 239,0 & 0,0 & 154,1 & 4,0 & 104,0 & 15,0 & 63,2 & 47,9 & 106,6 \\
\hline IRV & 11 & 22,1 & 176,4 & 8,8 & 16,6 & 54,2 & 88,4 & 112,0 & 8,6 & 84,9 & 154,1 & 0,0 & 158,1 & 50,0 & 139,1 & 90,9 & 106,2 & 47,5 \\
\hline EALT & 12 & 180,2 & 18,2 & 166,9 & 141,5 & 104,0 & 246,5 & 46,1 & 149,5 & 243,0 & 4,0 & 158,1 & 0,0 & 108,1 & 19,0 & 67,2 & 52,0 & 110,7 \\
\hline RODOBENSIMOB & 13 & 72,1 & 126,3 & 58,8 & 33,4 & 4,1 & 138,5 & 62,0 & 41,5 & 135,0 & 104,0 & 50,0 & 108,1 & 0,0 & 89,0 & 40,9 & 56,1 & 2,6 \\
\hline ROSSI RESID & 14 & 161,2 & 37,3 & 147,9 & 122,5 & 84,9 & 227,5 & 27,1 & 130,5 & 224,0 & 15,0 & 139,1 & 19,0 & 89,0 & 0,0 & 48,2 & 32,9 & 91,6 \\
\hline TECNISA & 15 & 113,0 & 85,5 & 99,7 & 74,3 & 36,7 & 179,3 & 21,1 & 82,3 & 175,8 & 63,2 & 90,9 & 67,2 & 40,9 & 48,2 & 0,0 & 15,3 & 43,5 \\
\hline TEN & 16 & 128,3 & 70,2 & 115,0 & 89,5 & 52,0 & 194,6 & 5,8 & 97,6 & 191,1 & 47,9 & 106,2 & 52,0 & 56,1 & 32,9 & 15,3 & 0,0 & 58,7 \\
\hline & 17 & 69,5 & 128,9 & 56,2 & 30,8 & 6,7 & 135,9 & 64,5 & 38,9 & 132,4 & 106,6 & 47,5 & 110,7 & 2,6 & 91,6 & 43,5 & 58,7 & 0,0 \\
\hline N. d & & 6 & 10 & 5 & 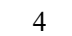 & 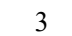 & 10 & 4 & 4 & 10 & 7 & 4 & 7 & 3 & 7 & ? & 3 & 3 \\
\hline
\end{tabular}

Fonte: dados da pesquisa.

Tabela 10 - Comparações múltiplas entre empresas - Margem Líquida

\begin{tabular}{|c|c|c|c|c|c|c|c|c|c|c|c|c|c|c|c|c|c|c|}
\hline EMPF & CÓD & & 2 & 3 & 4 & 5 & 6 & 7 & 8 & 9 & 10 & 11 & 12 & 13 & 14 & 15 & 16 & 17 \\
\hline CONST A LIND & 1 & 0,0 & 213,3 & 40,5 & 62,3 & 78,4 & 63,5 & 171,8 & 72,5 & 77,4 & 198,3 & 29,3 & 222,4 & 98,5 & 199,5 & 109,7 & 156,2 & 99,8 \\
\hline CR2 & 2 & 213,3 & 0,0 & 172,8 & 151,0 & 134,9 & 276,8 & 41,5 & 140,8 & 136,0 & 15,0 & 184,0 & 9,1 & 114,8 & 13,8 & 103,6 & 57,1 & 113,5 \\
\hline CYRELA REALT & 3 & 40,5 & 172,8 & 0,0 & 21,8 & 37,9 & 104,0 & 131,2 & 32,0 & 36,8 & 157,7 & 11,3 & 181,9 & 58,0 & 159,0 & 69,1 & 115,7 & 59,2 \\
\hline DIRECIONAL & 4 & 62,3 & 151,0 & 21,8 & 0,0 & 16,1 & 125,8 & 109,5 & 10,2 & 15,0 & 136,0 & 33,0 & 160,1 & 36,2 & 137,2 & 47,4 & 93,9 & 37,5 \\
\hline VEN & 5 & 78,4 & 134,9 & 37,9 & 16,1 & 0,0 & 141,9 & 93,4 & 5,9 & 1,0 & 119,9 & 49,1 & 144,0 & 20,1 & 121,1 & 31,3 & 77,8 & 21,4 \\
\hline EZTEC & 6 & 63,5 & 276,8 & 104,0 & 125,8 & 141,9 & 0,0 & 235,2 & 136,0 & 140,8 & 261,7 & 92,7 & 285,9 & 162,0 & 263,0 & 173,1 & 219,7 & 163,2 \\
\hline AFISA & 7 & 171,8 & 41,5 & 131,2 & 109,5 & 93,4 & 235,2 & 0,0 & 99,3 & 94,4 & 26,5 & 142,5 & 50,6 & 73,2 & 27,7 & 62,1 & 15,5 & 72,0 \\
\hline EI & 8 & 2,5 & 140,8 & 32,0 & 10,2 & 5,9 & 136,0 & 99,3 & 0,0 & 4,9 & 125,8 & 43,2 & 149,9 & 26,0 & 127,0 & 37,2 & 83,7 & 27,3 \\
\hline HSF & 9 & 7,4 & 136,0 & 36,8 & 15,0 & 1,0 & 140,8 & 94,4 & 4,9 & 0,0 & 120,9 & 48,1 & 145,0 & 21,2 & 122,1 & 2,3 & 78,9 & 22,4 \\
\hline $\mathrm{A}$ & 10 & 198,3 & 15,0 & 157,7 & 136,0 & 119,9 & 261,7 & 26,5 & 125,8 & 120,9 & 0,0 & 169,0 & 24,1 & 99,7 & 1,2 & 8,6 & 42,0 & 98,5 \\
\hline IRV & 11 & 29,3 & 184,0 & 11,3 & 33,0 & 49,1 & 92,7 & 142,5 & 43,2 & 48,1 & 169,0 & 0,0 & 193,1 & 69,3 & 170,2 & 80,4 & 127,0 & 70,5 \\
\hline PDG & 12 & 222,4 & 9,1 & 181,9 & 160,1 & 144,0 & 285,9 & 50,6 & 149,9 & 145,0 & 24,1 & 193,1 & 0,0 & 123,9 & 22,9 & 112,7 & 66,2 & 122,6 \\
\hline RODC & 313 & 98,5 & 114,8 & 58,0 & 36,2 & 20,1 & 162,0 & 73,2 & 26,0 & 21,2 & 99,7 & 69,3 & 123,9 & 0,0 & 101,0 & 11,1 & 57,7 & 1,2 \\
\hline ROSSI RESID & 14 & 199,5 & 13,8 & 159,0 & 137,2 & 121,1 & 263,0 & 27,7 & 127,0 & 122,1 & 1,2 & 170,2 & 22,9 & 101,0 & 0,0 & 89,8 & 43,3 & 99,7 \\
\hline TECNISA & 15 & 109,7 & 103,6 & 69,1 & 47,4 & 31,3 & 173,1 & 62,1 & 37,2 & 32,3 & 88,6 & 80,4 & 112,7 & 11,1 & 89,8 & 0,0 & 46,5 & 9,9 \\
\hline TENI & 16 & 156,2 & 57,1 & 115,7 & 93,9 & 77,8 & 219,7 & 15,5 & 83,7 & 78,9 & 42,0 & 127,0 & 66,2 & 57,7 & 43,3 & 46,5 & 0,0 & 56,5 \\
\hline TRI & 17 & 99,8 & 113,5 & 59,2 & 37,5 & 21,4 & 163,2 & 72,0 & 27,3 & 22,4 & 98,5 & 70,5 & 122,6 & 1,2 & 99,7 & 9,9 & 56,5 & 0,0 \\
\hline N. de di & & 6 & 8 & - & 5 & 5 & 13 & 4 & 5 & 6 & 0 & 6 & 10 & 2 & 8 & 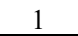 & 3 & \\
\hline
\end{tabular}

Fonte: dados da pesquisa. 